\title{
Reform and innovation in human services and policing: Vital investments in community trust and well-being
}

\author{
Norman E. Taylor*
}

Welcome to our special themed issue on systemic reform, a term that has gained significant profile in this troubled year. We hope to continue this theme through subsequent issues, and our open call for papers is ongoing in support of this broad arena of system innovation. We are also entering the run-up period to the sixth global Law Enforcement and Public Health (LEPH) conference, along with a variety of related virtual learning and engagement events coming this winter and early spring. Our Journal of Community Safety and Well-Being will again provide an important showcase for many of the conference's presenters, their featured research projects, and their innovative propositions for reform.

I have expressed a lot of my own thoughts on the growing urgency for long overdue change, in particular throughout much of this unusual year. Most recently, in an Editor's Corner piece in our Dispatch Newsletter titled Taking the Plunge into Systemic Reform ... an Inevitable and Overdue End to Sameness (Taylor, 2020), I made a case for tilting our own editorial direction more aggressively. Now, in this issue, we let the articles carefully curated by our editorial team do the talking.

Some will simply inform deeper conversations yet to come. Many will inspire. A few might make you uncomfortable and maybe even a bit angry, depending on your current mindset, or depending on the culture in which you have invested your career.

Regular readers might notice that, for this special issue, we have suspended our use of three of our regular editorial sections, Strengths, Services, and Justice, in favour of assembling all of our featured papers on systemic reform under the single section, Trust.

It is our view that at its core, systemic reform must essentially be about restoring trust. It has now become our most apparent and urgent social imperative to repair the reciprocal levels of trust between all global citizens and publicly funded human services, community-based resources, and the prevailing economic and political structures that are meant to serve them.
Without trust, these elements will become increasingly unable to nurture and support community, family, and individual strengths. Without trust, meaningful services will fail to align with real needs and will present continuing deterrents and barriers to those hoping and needing to access them. Without trust, justice is merely a state apparatus, disconnected from genuine human aspirations and equitable outcomes.

For those who work within these systems, we know we can all come up with a lot of reasons for staying the course, for preserving all those sacred myths that shape and protect the behaviours, the comforts, and the choices that define each and every sector of health and human services, policing and criminal justice, economic opportunity and social equity. We have finely parsed them out over the past several decades, in the pursuit of their respective administrative logic, simplicity of operations and budgetary accountability, and cautious fealty to still prevailing yet often tacit colonial assumptions about power, privilege, and prosperity.

Today, as the year 2020 draws to a close, literally nothing is resolved. Yet there is a global abundance of knowledge and thought, hard science and social science, evidence and promise, that can help us all find and implement innovative ways forward.

If only we could all relax our obstinate grip on normal. It most certainly appears to have relaxed its grip on us.

\section{CONFLICT OF INTEREST DISCLOSURES}

The author has continuing business interests that include providing advisory services to communities, police services and related human service agencies.

\section{AUTHOR AFFILIATIONS \\ * Editor-in-Chief}

\section{REFERENCES}

Taylor, N. E. (2020). Taking the plunge into systemic reform ... an inevitable and overdue end to sameness. The Dispatch. https://madmimi. $\mathrm{com} / \mathrm{s} / \mathrm{d} 839711$

Correspondence to: Norman E. Taylor, Community Safety Knowledge Alliance, 120 Sonnenschein Way - Main, Saskatoon, SK S7M OW2

E-mail: ntaylor@cskacanada.ca

To cite: Taylor, N. E. (2020). Reform and innovation in human services and policing: Vital investments in community trust and well-being. Journal of Community Safety and Well-Being, 5(4), 135. https://doi.org/10.35502/jcswb.174

(C) Author(s) 2020. Open Access. This work is distributed under the Creative Commons BY-NC-ND license. For commercial re-use, please contact sales@sgpublishing.ca. gPUBLISHING Published by SG Publishing Inc. CSKA Official publication of the Community Safety Knowledge Alliance. 